\title{
Tannic acid attenuates hepatic oxidative stress, apoptosis and inflammation by activating the Keap1-Nrf2/ARE signaling pathway in arsenic trioxide-toxicated rats
}

\author{
MENGYING LI ${ }^{1}$, PANPAN LIU ${ }^{1}$, YUCONG XUE ${ }^{1}$, YINGRAN LIANG ${ }^{1}$, JING SHI $^{2}$, \\ $\mathrm{XUE} \mathrm{HAN}^{1}$, JIANPING ZHANG ${ }^{3,4}, \mathrm{XI} \mathrm{CHU}^{2}$ and $\mathrm{LI} \mathrm{CHU}^{1,4}$ \\ ${ }^{1}$ School of Pharmacy, Hebei University of Chinese Medicine, Shijiazhuang, Hebei 050200; \\ ${ }^{2}$ Department of Pharmacy, The Fourth Hospital of Hebei Medical University, Shijiazhuang, Hebei 050011; \\ ${ }^{3}$ School of Basic Medicine; ${ }^{4}$ Hebei Key Laboratory of Integrative Medicine on Liver-Kidney Patterns, \\ Hebei University of Chinese Medicine, Shijiazhuang, Hebei 050200, P.R. China
}

Received March 12, 2020; Accepted August 13, 2020

DOI: 10.3892/or.2020.7764

\begin{abstract}
The present study was performed to investigate the protective effects of tannic acid (TA) on liver injury induced by arsenic trioxide (ATO) and to elucidate the mechanism involved as related to the Kelch-like ECH-associated protein 1 (Keap1)-nuclear factor erythroid 2-related factor 2 (Nrf2)/antioxidant response element (ARE) signaling pathway. Adult rats were intraperitoneally injected with TA, while ATO was administered $1 \mathrm{~h}$ later. On the 11th day, the rats were euthanized to determine any liver histological changes, liver function, and the activities of antioxidant, antiapoptosis and proinflammatory cytokines in the liver. Furthermore, the protein expression levels of nuclear Nrf2, total Nrf2, Keap1, Heme oxygenase-1 (HO-1), NADPH quinine oxidoreductase-1 (NQO1), and $\gamma$-glutamylcysteine synthetase $(\gamma$-GCS) were determined using western blot analysis. The results showed that TA treatment ameliorated ATO-induced liver histological changes and decreased the ATO-induced increased alanine aminotransferase (ALT) and aspartate transaminase (AST) serum levels. Activities of the antioxidant enzymes significantly were increased, while the levels of malondialdehyde (MDA) and reactive oxygen species (ROS) were attenuated following TA treatment. In addition, TA treatment inhibited ATO-induced liver apoptosis and inflammatory responses, increased $\mathrm{Bcl}-2$ protein expression level and reduced the
\end{abstract}

Correspondence to: Dr Xi Chu, Department of Pharmacy, The Fourth Hospital of Hebei Medical University, 12 Jiankang Road, Shijiazhuang, Hebei 050011, P.R. China

E-mail: chux2014@126.com

Professor Li Chu, School of Pharmacy, Hebei University of Chinese Medicine, 3 Xingyuan Road, Luquan, Shijiazhuang, Hebei 050200, P.R. China

E-mail: chuli0614@126.com

Key words: tannic acid, arsenic trioxide, hepatotoxicity, Nrf2 levels of Bax, caspase-3, interleukin (IL)-1 $\beta$, IL- 6 and tumor necrosis factor (TNF)- $\alpha$. Furthermore, TA treatment increased the protein expression levels of Nrf2 and Keap1, HO-1, NQO1 and $\gamma$-GCS. The results demonstrated that TA has a protective effect on ATO-treated hepatic toxicity and that its underlying mechanism could be due to TA activation of the Keap1-Nrf2/ARE signaling pathway, to reduce oxidative stress, apoptosis and inflammation in ATO-intoxicated rats.

\section{Introduction}

Arsenic trioxide (ATO; $\mathrm{As}_{2} \mathrm{O}_{3}$ ) is a well-known toxin, that occurs in the environment and is also a common medicine against a wide variety of solid tumors, such as acute promyelocytic leukemia. However, the adverse drug reactions of ATO severely limit its clinical application (1). ATO is water-soluble and can be absorbed readily into the bloodstream. As a site of first-pass metabolism, the liver is exposed to ATO, at high levels, first and then ATO is distributed for systemic circulation among other organs and tissues (2). The liver is a principal detoxification organ for ATO, as it undergoes reduction and oxidative methylation in the hepatocytes and is then excreted out. Furthermore, ATO binds to biological ligands containing sulfur groups and enhances reactive oxygen species (ROS) (3). The liver is the primary organ subjected to ATO effects which is damaged by oxidative stress and an abnormal liver function manifests as elevated serum enzymes (4). Several studies have reported a hypothesis that ATO could promote oxidative stress, apoptosis and inflammation $(5,6)$. The transcription factor nuclear factor erythroid-2 related factor 2 (Nrf2)/antioxidant response element (ARE) signaling pathway has been considered as the major cellular defense against oxidative stress $(7,8)$ and is considered to be a novel therapeutic target to treat liver disease (9). Stimulated by oxidative stress, Nrf2 dissociates from Kelch-like ECH-related protein1 (Keapl) in the cytoplasm and transfers to the nucleus, where it exhibits its antioxidant action and upregulates various cytoprotective proteins (10). The downstream targets of Nrf2 include Heme oxygenase-1 (HO-1), NADPH quinine 
oxidoreductase-1 (NQO1), $\gamma$-glutamylcysteine synthetase $(\gamma$-GCS) and superoxide dismutase (SOD), which are stimulated by Nrf2 and then exert their antioxidative effects $(10,11)$. Therefore, antioxidants, particularly Nrf2 inhibitors, may play important roles in preventing ATO damage or intoxication.

Tannic acid (TA; $\mathrm{C}_{76} \mathrm{H}_{52} \mathrm{O}_{46}$ ) (Fig. 1) is a light-brown natural compound, and is found in high amounts in various fruits, vegetables and medicinal plants (12). TA can chelate with metal ions and interact with biological macromolecules such as proteins, alkaloids, and polysaccharides. The structure of pyrogallol can be easily oxidized to a quinone structure, which provides TA with a supply of hydrogen and becomes oxidation resistant. Previous reports have shown that TA has multiple pharmacological activities, such as antioxidative, anti-inflammatory, antibacterial, anticarcinogenic and antimutagenic properties $(13,14)$. Our previous studies have shown that TA exerts its protective effects against ATO-induced nephrotoxicity through NF- $\mathrm{KB}$ and Nrf2 pathways (15) and carbon tetrachloride and acetaminophen-induced hepatotoxicity $(16,17)$. In addition, other experimental evidence also shows that TA plays an important role in the treatment of some hepatotoxicity and liverish conditions (18) and stimulates the role of the Nrf2-Keap1 signaling pathway in phase II and the gene expression of antioxidation proteins in HepG2 cells (19). At the same time, based on the protective effect of TA on acetaminophen-induced hepatic toxicity in mice, which was found in our previous study (17), we hypothesize that TA could improve ATO-induced hepatic damage through the Keap1-Nrf2/ARE signaling pathway. However, to date, confirmation of this hypothesis has not been carried out.

In the present study, an ATO-induced liver injury model in rats was established and the protective effects of TA on oxidative stress and hepatic toxicity were subsequently investigated. The regulation of TA in the Nrf2 signaling pathway was also studied, as well as its downstream targets to determine the protective effect of TA on ATO-induced hepatic toxicity and the underlying mechanisms related to the Keap1-Nrf2/ARE signaling pathway. Therefore, the present study suggests that TA may suppress ATO-induced hepatic toxicity by activating the Keap1-Nrf2/ARE signaling pathway, providing a possible therapeutic drug for clinical treatment of ATO-induced hepatotoxicity.

\section{Materials and methods}

Drugs and reagents. TA, at manufacturer's standard and analytical purity, was obtained from Jinbei Fine Chemical Co., Ltd. ATO was purchased from Shuanglu Medicine Factory (Beijing, China). Alanine aminotransferase (ALT), aspartate transaminase (AST), superoxide dismutase (SOD), malondialdehyde (MDA), catalase (CAT) and glutathione peroxidase (GSH-Px) kits were purchased from Nanjing Jiancheng Bioengineering Institute. Antibodies against Bax (cat. no. AF0120), Bcl-2 (cat. no. AF6139) were purchased from Affinity Biosciences. Antibodies against IL-1 $\beta$ (cat. no. BS6067), TNF- $\alpha$ (cat. no. BS6000), Lamin B1 (cat. no. AP6001), NQO1 (cat. no. BS90961) and $\gamma$-GCS (cat. no. BS90566) were purchased from Bioworld Technology. Antibodies against caspase-3 (cat. no. 19677-1-AP), Keap1 (cat. no. 90503-2-AP), HO-1 (product code 10701-1-AP) and Nrf2 (product code 16396-1-AP) were purchased from
Proteintech Group, Inc. Antibodies against IL-6 (product code ab9324) was obtained from Abcam Biotechnology, and $\beta$-actin (product code CST3700) was purchased from Cell Signaling Technology. Unless otherwise indicated, the remaining chemicals were provided by Sigma Chemical Co.

Animals and experimental protocol. Fifty male adult Sprague-Dawley rats (weight, $200 \pm 20 \mathrm{~g}$; age, 12-week-old), purchased from the Experimental Animal Center of Hebei Medical University, were raised under standard conditions at room temperature, $45-55 \%$ relative humidity and a $12-\mathrm{h}$ light-dark cycle. All operations were approved by the Animal Experiment Ethics Committee of Hebei University of Chinese Medicine (approval no. DWLL2016001).

A total of 50 rats were evenly divided into five groups: Control group (normal saline), ATO group ( $5 \mathrm{mg} / \mathrm{kg} \mathrm{ATO}$ ), L-TA group (20 mg/kg TA $+5 \mathrm{mg} / \mathrm{kg}$ ATO), H-TA group $(40 \mathrm{mg} / \mathrm{kg} \mathrm{TA}+5 \mathrm{mg} / \mathrm{kg}$ ATO) and TA group ( $40 \mathrm{mg} / \mathrm{kg} \mathrm{TA})$. Based on the literature and our preliminary experiment, 20 or $40 \mathrm{mg} / \mathrm{kg}$ of TA were used for the animal experiment (20). TA was administered orally $1 \mathrm{~h}$ prior to ATO intraperitoneal treatment once a day. During the treatment, the weight and behavior of rats were monitored daily. The entire course lasted for 10 days (21), and the humane endpoint in our program was defined as weight loss $>10 \%$, anorexia or lethargy. It is worth noting that all 50 rats remained alive during this period and were euthanized. The animals were anesthetized using sodium pentobarbital $(50 \mathrm{mg} / \mathrm{kg}), 24 \mathrm{~h}$ after the last treatment following which, blood sampling from the femoral artery $(\sim 5-7 \mathrm{ml}$ each sample) in the rat were quickly collected. The euthanasia of the rats was carried out by overdose with intraperitoneal injection of sodium pentobarbital $(200 \mathrm{mg} / \mathrm{kg}$ ) and was confirmed by observing the absence of respiration and heartbeat, and liver tissues were quickly collected for further analysis.

Histological analysis. In order to evaluate the histopathological manifestations in the liver, in the experimental groups of the rats, the liver tissues were obtained, immobilized overnight with $10 \%$ neutral buffered formalin, dehydrated, embedded in paraffin and cut into sections. Slices were stained with hematoxylin and eosin (H\&E) and observed using a Leica DM4000B microscope (Solms, Germany).

Colorimetric analysis. To obtain the serum from the blood, the samples were centrifuged at 2,200 $\mathrm{x}$ g for $10 \mathrm{~min}$ at $37^{\circ} \mathrm{C}$. Serum ALT, AST, SOD, MDA, CAT and GSH-Px levels were measured according to the manufacturer's instructions. Finally, the absorbance was measured using a Varioskan LUX Multimode Reader (Thermo Fisher Scientific, Inc.).

Fluorescence microscopy. To enable evaluation of the level of ROS in the liver, the liver tissues were stained with $10 \mathrm{nM}$ dihydroethidium (DHE) at room temperature for $30 \mathrm{~min}$ and then observed using an optical microscope (DM5000B; Leica, Germany) at a condition of Ex/Em=518 nm/605 nm. The intensity of ROS, from the digital images was analyzed by Image-Pro Plus 6.0 (Media Cybernetics).

Western blot analysis. Liver tissues were homogenized and lysed using a RIPA lysis buffer (Solarbio, China) to obtain 
<smiles>O=C(OC[C@H]1O[C@H](OC(=O)c2cc(OC(=O)c3cc(O)c(O)c(O)c3)cc(C(=O)Oc3cc(O)c(O)c(O)c3)c2)[C@H](OC(=O)c2cc(O)c(O)c(O)c2)[C@@H](OC(=O)c2cc(O)c(O)c(OC(=O)c3cc(O)c(O)c(O)c3)c2)[C@@H]1OC(=O)c1cc(O)c(O)c(OC(=O)c2cc(O)c(O)c(O)c2)c1)c1cc(O)c(O)c(OC(=O)c2cc(O)c(O)c(O)c2)c1</smiles>

Figure 1. Chemical structure of tannic acid (TA).

proteins. Protein concentrations were determined using BCA kits. SDS-PAGE gel (10\%) was used to separate the equal amounts of the protein $(30 \mu \mathrm{g})$ and then the protein was electrotransferred onto a PVDF membrane. The membrane was subsequently incubated with the primary antibodies (dilution 1:1,000) overnight at $4^{\circ} \mathrm{C}$, and then incubated with the secondary antibodies (dilution 1:3,000) at $37^{\circ} \mathrm{C}$ for $90 \mathrm{~min}$. Immunoreactive proteins were detected using an enhanced chemiluminescence light detection kit (ZSGBBIO, China). Following which, the gray value of the blots was determined using Tanon Gis software (ver. 4.00; Tanon).

Terminal deoxynucleotidyl-transferase-mediated dUTP nickend labelling (TUNEL) assay. TUNEL assay was used to detect hepatocyte apoptosis in the liver sections.4,6-Diamino-2-phenylindole (DAPI, $1 \mathrm{mg} / \mathrm{ml}$ ) was used for staining for $10 \mathrm{~min}$, and DAB was subsequently used also for staining. Following which, the slices were re-stained with hematoxylin, dehydrated using alcohol hydrochloride, blocked with a neutral gel and observed using a light microscope (magnification, $\mathrm{x} 400$ ). Cells stained brown in the nucleus were considered positive.
Statistical analysis. Statistical analysis was performed using the Statistical Package for Social Sciences software (v16.0; SPSS, Inc.). Data are expressed as the mean \pm SEM. Statistical differences were assessed using one-way analysis of variance (ANOVA) followed by the Tukey's post hoc test. $\mathrm{P}<0.05$ was considered to indicate a statistically significant difference.

\section{Results}

Effects of TA on liver histological changes in ATO-treated rats. $\mathrm{H} \& \mathrm{E}-\mathrm{stained}$ sections of the livers were observed using an optical microscope, around the structures of the hepatic central vein area (Fig. 2A) and hepatic duct area (Fig. 2B). The control rats demonstrated normal histological structure. The central vein was radiating and arranged by the hepatic cord or plate. The hepatic duct area is composed of the interlobular artery, interlobular vein and interlobular bile duct. Liver histological sections in the ATO group showed inflammatory cell infiltration, hepatic sinus dilatation and congestion, mild atrophy of hepatocytes and a mild narrow hepatic plate around the 
A
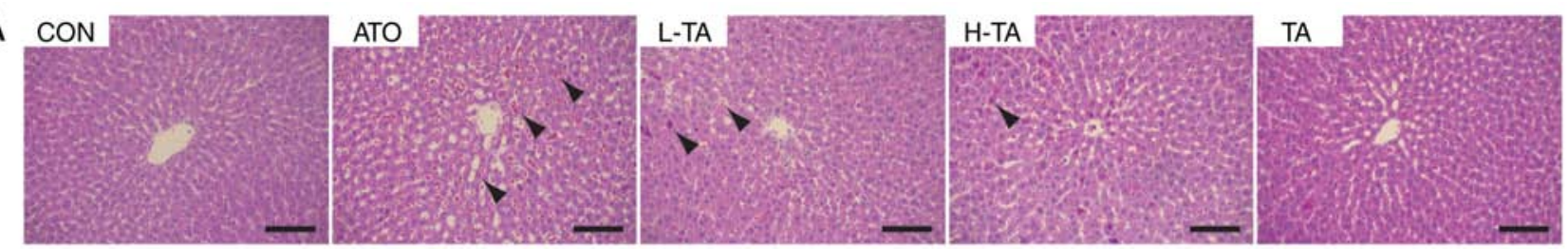

B
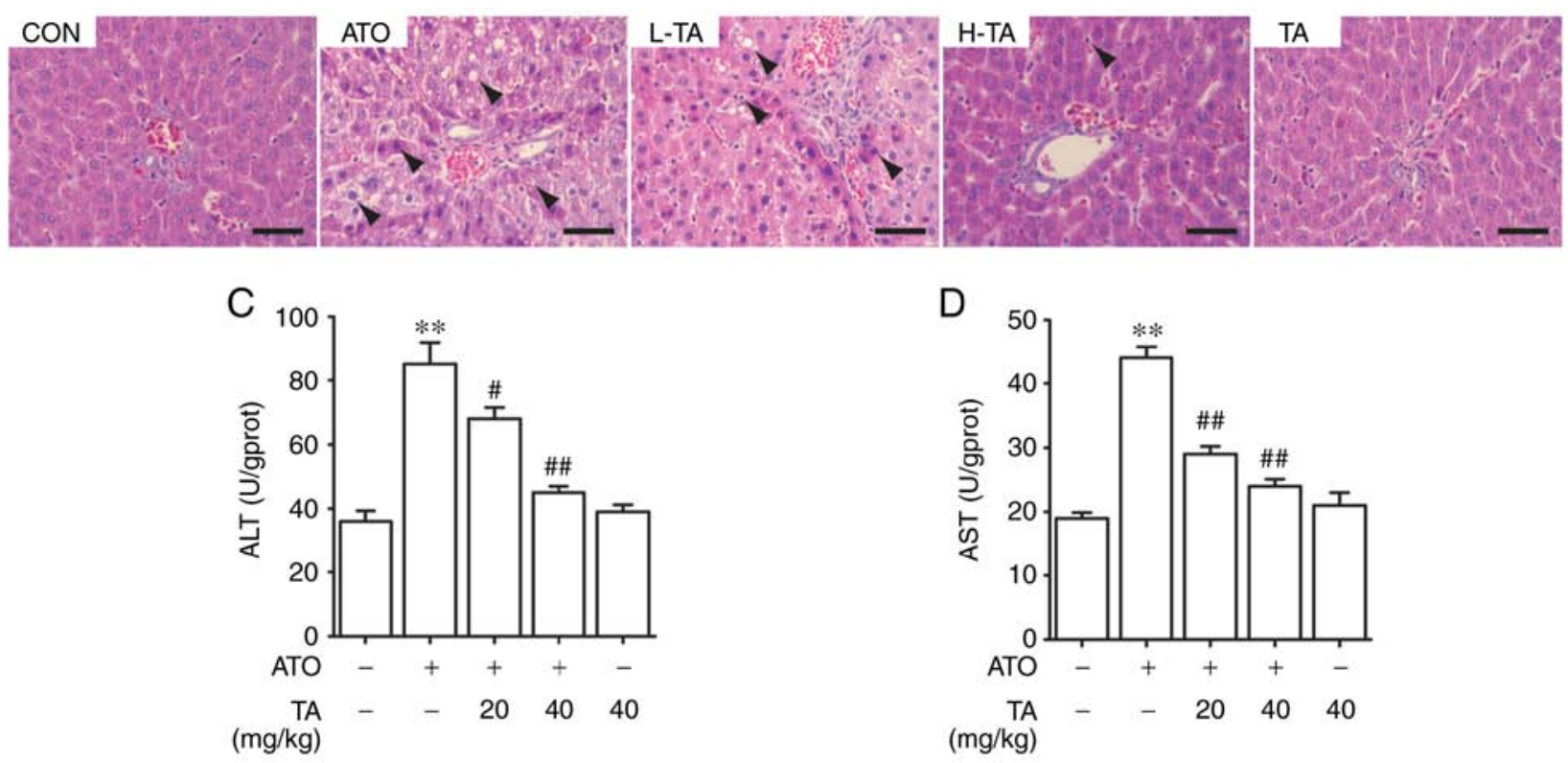

Figure 2. Effects of TA on hepatic damage in ATO-exposed rats. Representative sections of H\&E staining in the (A) hepatic central vein area (magnification $\mathrm{x} 200$ ) and (B) hepatic duct area (magnification x400) in rats. Arrows indicate the lesion area of the liver. Scale bar, $50 \mu \mathrm{m}$. (C) ALT and (D) AST levels of serum in rats. All results are presented as the mean \pm SEM $(n=4) .{ }^{* *} \mathrm{P}<0.01$ vs. the control group; ${ }^{\#} \mathrm{P}<0.05,{ }^{\# \#} \mathrm{P}<0.01$ vs. the ATO group. TA, tannic acid; ATO, arsenic trioxide; ALT, alanine aminotransferase; AST, aspartate transaminase; H\&E, hematoxylin and eosin. Groups included: Control group (CON) (normal saline), ATO group (5 mg/kg ATO), L-TA group (20 mg/kg TA + 5 mg/kg ATO), H-TA group (40 mg/kg TA + 5 mg/kg ATO) and TA group (40 mg/kg TA).

central vein. Furthermore, the pathological findings regarding the portal tract included edema of hepatocytes, cytoplasmic vacuolization, lipid droplets of varying sizes in the cytoplasm and apoptosis with chromatic agglutination and karyopyknosis. ATO-induced rats treated with 20 or $40 \mathrm{mg} / \mathrm{kg}$ TA showed improved histological structure of the livers. Observation of the liver sections in these two groups suggested that TA markedly prevented liver steatosis, congestion and hepatocyte apoptosis. The liver histological sections in the TA group were similar compared with that in the control group, suggesting that $40 \mathrm{mg} / \mathrm{kg}$ TA had few noxious side effects in the rats.

Effects of TA on the activation of ALT and AST levels in ATO-treated rats. ALT and AST are considered to be circulating liver function markers. The effect of TA on the levels of ALT and AST in the control and ATO-treated rats is represented in Fig. 2C and D. Compared with that in the control group, ATO-induced levels of ALT and AST in rats were significantly increased in the serum $(\mathrm{P}<0.01)$, while rats that received only $40 \mathrm{mg} / \mathrm{kg}$ TA showed non-significant changes in the levels of the serum liver function markers $(\mathrm{P}>0.05)$. Treatment of the ATO-induced rats with 20 or $40 \mathrm{mg} / \mathrm{kg}$ TA significantly ameliorated the increased levels of ALT and AST levels in the serum $(\mathrm{P}<0.05$ or $\mathrm{P}<0.01)$.

Effects of TA on ROS in ATO-treated rats. The effect of TA on ROS fluorescence intensity in the control and treated rats is represented in Fig. 3A. The intensity induced by ATO was significantly higher than that in the control group $(\mathrm{P}<0.01)$. However, TA effectively removed ROS induced by ATO $(\mathrm{P}<0.01)$. Rats that received only $40 \mathrm{mg} / \mathrm{kg}$ TA showed non-significant changes when compared to the control group. The semi-quantitative and statistical results of each group are shown in Fig. 3B.

Effects of TA on the activities of antioxidant enzymes in ATO-treated rats. ATO-exposed rats showed a marked decrease in the levels of SOD, CAT and GSH-Px in the serum as shown in Fig. 4A-D $(\mathrm{P}<0.01)$. TA rejuvenated the levels of SOD, CAT and GSH-Px in ATO-induced rats when supplemented at 20 or $40 \mathrm{mg} / \mathrm{kg}(\mathrm{P}<0.05$ or $\mathrm{P}<0.01)$. On the other hand, the lipid peroxidation marker MDA in the ATO-induced rats was significantly increased when compared to the control group $(\mathrm{P}<0.01)$. Treatment with 20 or $40 \mathrm{mg} / \mathrm{kg}$ TA significantly decreased the MDA content in ATO-induced rat livers $(\mathrm{P}<0.01)$. When compared against the control group, rats that received only $40 \mathrm{mg} / \mathrm{kg}$ TA showed non-significant changes in the serum SOD, MDA, CAT and GSH-Px levels $(\mathrm{P}>0.05)$.

Effects of TA on apoptosis in ATO-treated rats. The effect of TA on apoptosis in the control and ATO-treated rats is represented in Fig. 5A. The apoptosis cells induced by ATO were significantly more than that of the control group $(\mathrm{P}<0.01)$. However, TA 

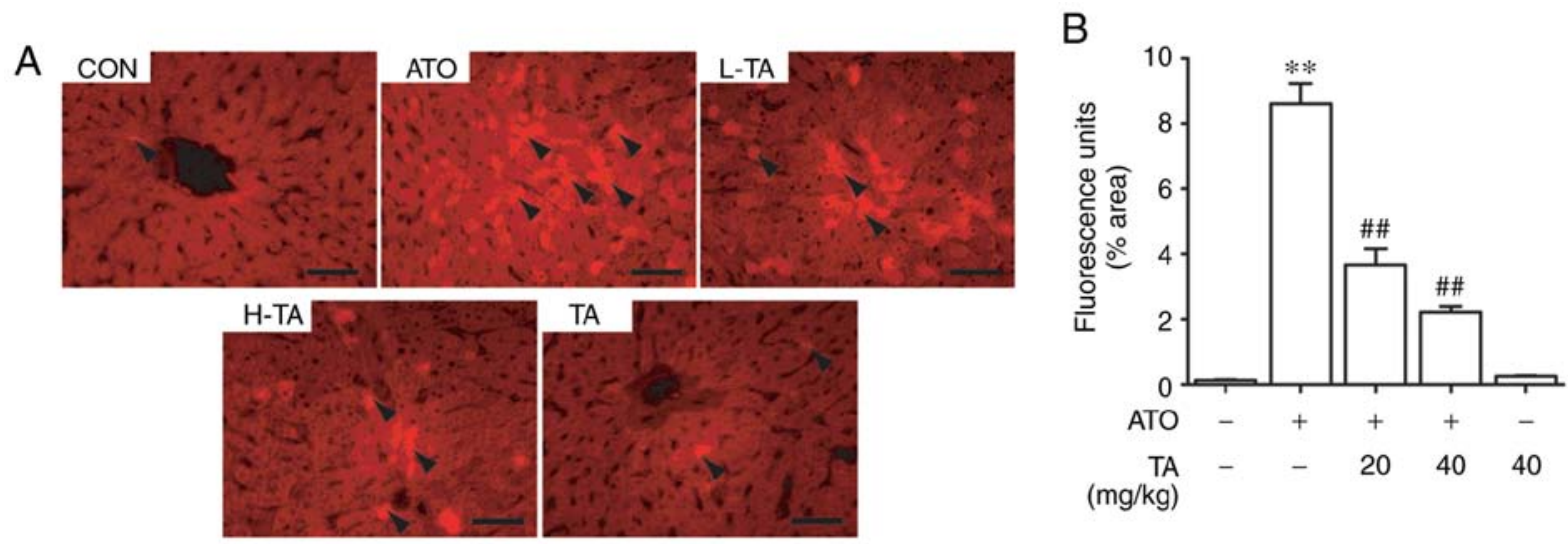

Figure 3. Effects of TA on ATO-exposed ROS in rats. (A) Representative sections of DHE staining of the liver in rats were assessed for ROS generation by detecting fluorescence intensity (magnification $\mathrm{x} 400$ ). Arrows indicate the lesion area of the liver. Scale bar, $50 \mu \mathrm{m}$. (B) DHE staining was used for semi-quantitative analysis of ROS production. ${ }^{* *} \mathrm{P}<0.01$ vs. control group; ${ }^{\# /} \mathrm{P}<0.01$ vs. ATO group. TA, tannic acid; ATO, arsenic trioxide; DHE, dihydroethidium; ROS, reactive oxygen species. Groups included: Control group (CON) (normal saline), ATO group (5 mg/kg ATO), L-TA group (20 mg/kg TA + $5 \mathrm{mg} / \mathrm{kg}$ ATO), H-TA group ( $40 \mathrm{mg} / \mathrm{kg} \mathrm{TA}+5 \mathrm{mg} / \mathrm{kg}$ ATO) and TA group (40 mg/kg TA).
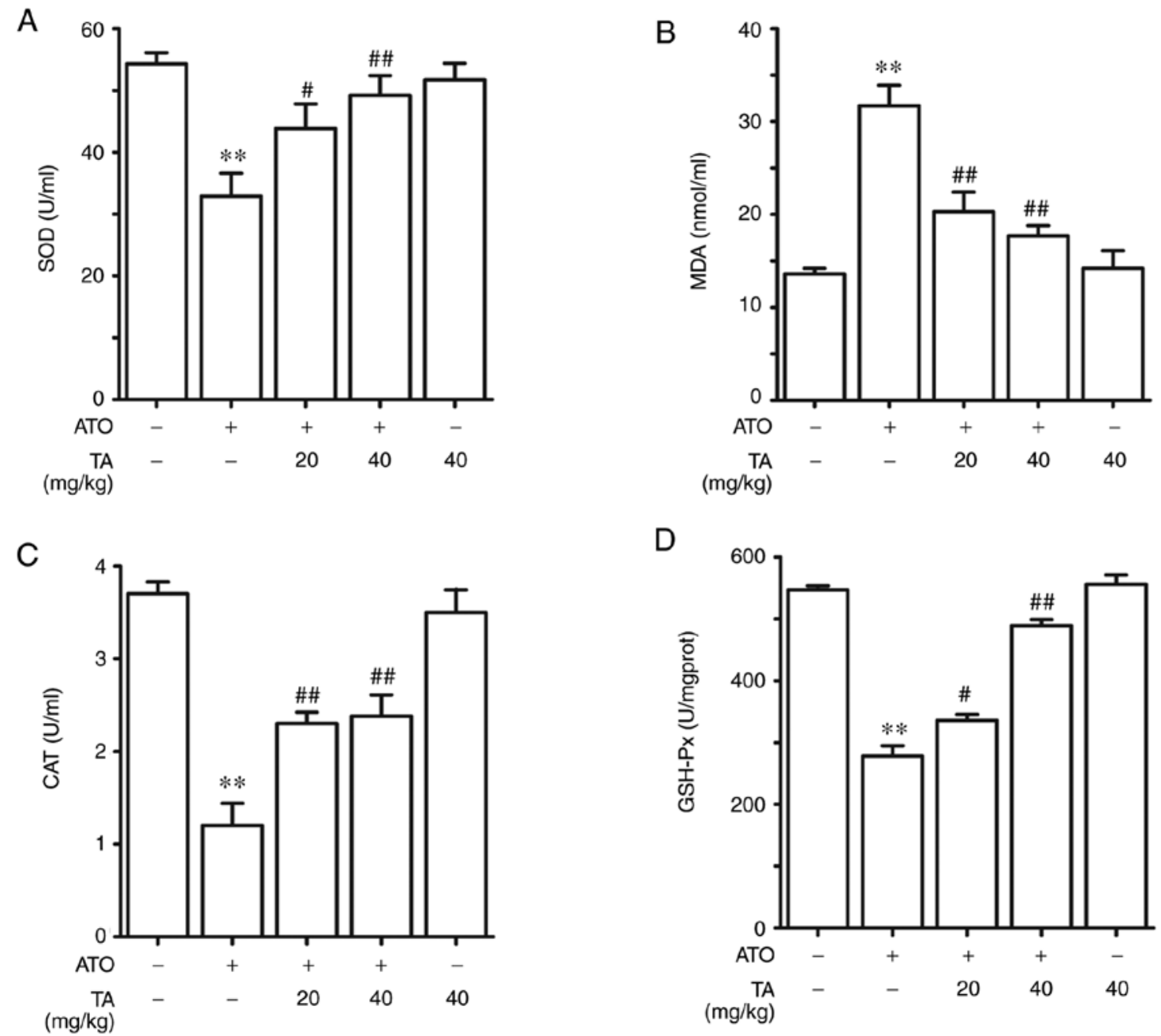

Figure 4. Effects of TA on the activities of antioxidant enzymes in ATO-exposed rats. The serum levels of (A) SOD, (B) MDA, (C) CAT and (D) GSH-Px in rats. All results are presented as the mean $\pm \mathrm{SEM}(\mathrm{n}=4) .{ }^{* *} \mathrm{P}<0.01$ vs. the control group; ${ }^{*} \mathrm{P}<0.05,{ }^{\# \#} \mathrm{P}<0.01$ vs. the ATO group. TA, tannic acid; ATO, arsenic trioxide; SOD, superoxide dismutase; MDA, malondialdehyde; CAT, catalase; GSH-Px, glutathione peroxidase.

effectively removed apoptosis induced by ATO $(\mathrm{P}<0.01)$. The semi-quantitative and statistical results of each group are shown in Fig. 5B. As shown in Fig. 5C-F, ATO-induced rats showed a marked decrease in the protein expression level of $\mathrm{Bcl}-2$ and an increase in Bax and caspase-3 levels $(\mathrm{P}<0.01)$. TA rejuvenated Bcl-2 and attenuated Bax and caspase- 3 of ATO-induced rats 
A

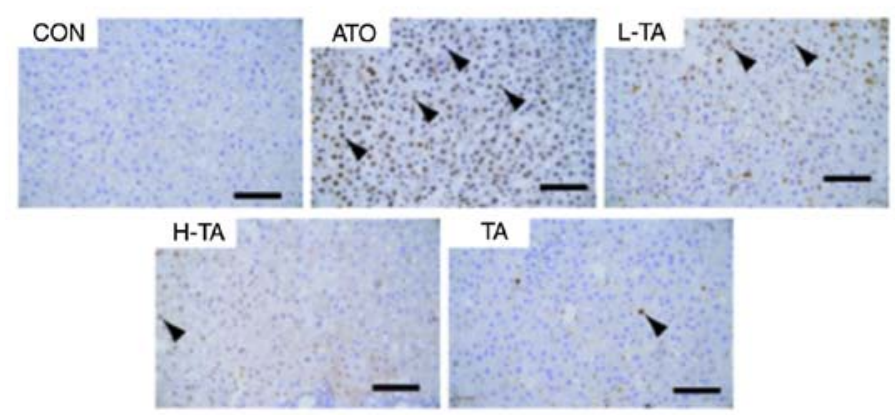

B

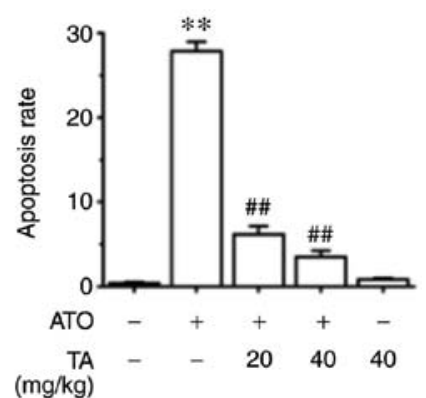

C

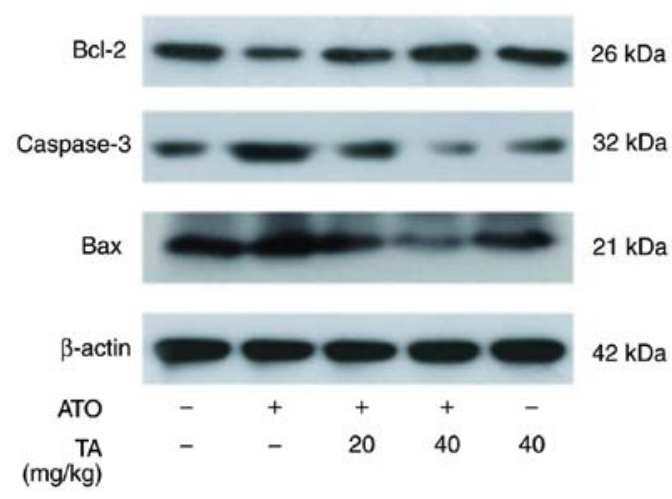

D

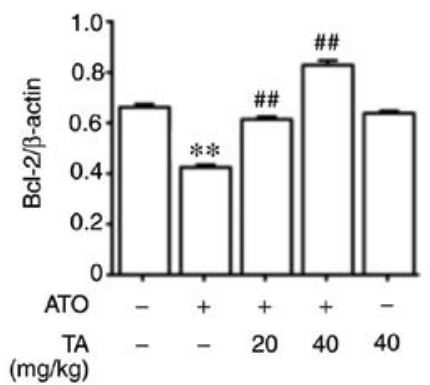

E

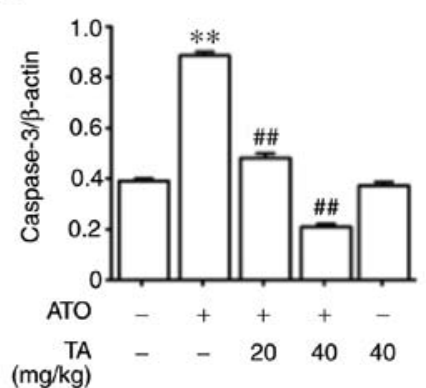

$\mathrm{F}$

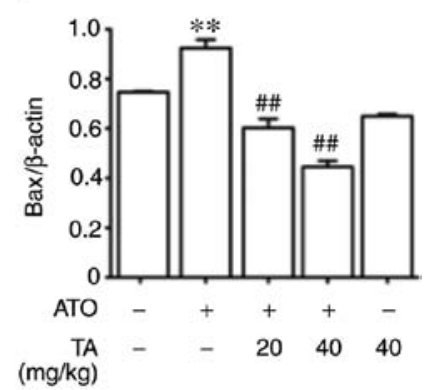

Figure 5. Effects of TA on ATO-exposed apoptosis in rats. (A) Apoptosis of rat liver cells was assessed by TUNEL staining (magnification x400). Arrows indicate apoptosis in the cells of the liver. Scale bar, $50 \mu \mathrm{m}$. (B) TUNEL staining was used for semiquantitative analysis of apoptotic cells. (C) Western blot analysis was used to assess the hepatic protein expression levels of (D) Bax, (E) Bcl-2 and (F) caspase-3. All results are presented as the mean \pm SEM ( $\mathrm{n}=4$ ). ${ }^{* *} \mathrm{P}<0.01$ vs. the control group; ${ }^{\# \#} \mathrm{P}<0.01$ vs. the ATO group. TA, tannic acid; ATO, arsenic trioxide; TUNEL, terminal deoxynucleotidyl-transferase-mediated dUTP nick end labelling.

when supplemented at 20 or $40 \mathrm{mg} / \mathrm{kg}(\mathrm{P}<0.01)$. Rats which only received $40 \mathrm{mg} / \mathrm{kg}$ TA showed non-significant changes in the apoptosis rate, $\mathrm{Bax}, \mathrm{Bcl}-2$ and caspase- 3 expression levels when compared to the control group $(\mathrm{P}>0.05)$.

Effects of TAoninflammation in ATO-treatedrats. ATO-induced rats showed a marked increase in the protein expression levels of interleukin (IL)-1 $\beta$, IL-6 and tumor necrosis factor (TNF)- $\alpha$ as shown in Fig. 6A-D $(\mathrm{P}<0.01)$. Treatment with 20 or $40 \mathrm{mg} / \mathrm{kg}$ TA significantly reduced the protein expression levels of IL-1 $\beta$, IL-6 and TNF- $\alpha$ in the rat livers in the ATO group $(\mathrm{P}<0.01)$. Rats that received only $40 \mathrm{mg} / \mathrm{kg}$ TA showed non-significant effect compared against the control group $(\mathrm{P}>0.05)$.

Effects of TA on Nrf2 activation in ATO-treated rats. The effect of TA on Nrf2 protein expression in control and ATO-treated rats is represented in Fig. 7A. Nrf2 was expressed only in the cytoplasm of the control group and the expression level was higher than that of the ATO group. Following treatment with 20 or $40 \mathrm{mg} / \mathrm{kg}$ TA, Nrf2 expression was increased in both the nucleus and the cytoplasm, prompting that TA led to Nrf2 translocation from the cytoplasm into the nucleus. As shown in Fig. 7B and C by western blot analysis, ATO decreased the cytoplasmic Nrf2 $(\mathrm{P}<0.01)$ while TA with 20 or $40 \mathrm{mg} / \mathrm{kg}$ regained it $(\mathrm{P}<0.01)$. Furthermore, TA treatment significantly activated nuclear Nrf2 $(\mathrm{P}<0.01)$, which was inhibited by ATO $(\mathrm{P}<0.01)$. Rats that received only $40 \mathrm{mg} / \mathrm{kg}$ TA also showed significantly activated nuclear Nrf2 compared with the control group $(\mathrm{P}<0.01)$.

Effects of TA on the expression levels of downstream targets in the Nrf2 signaling pathway in the ATO-treated rats. 
A
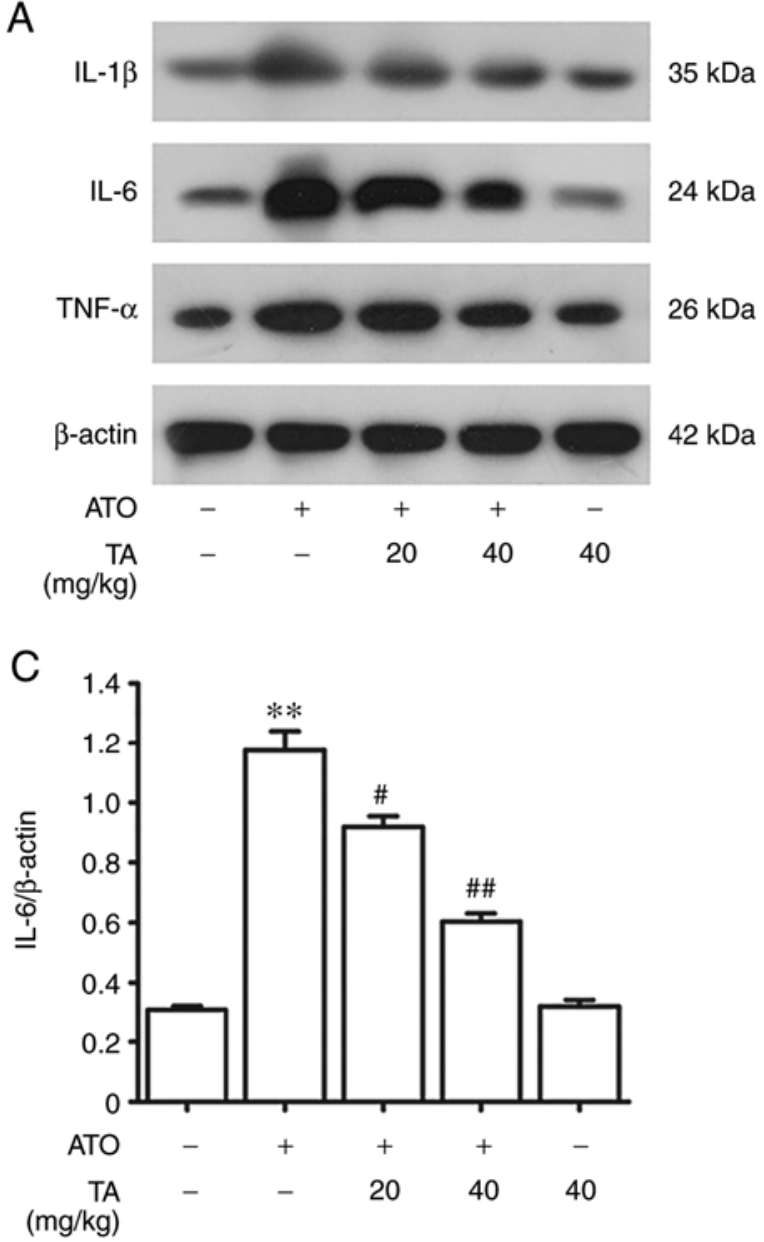

B
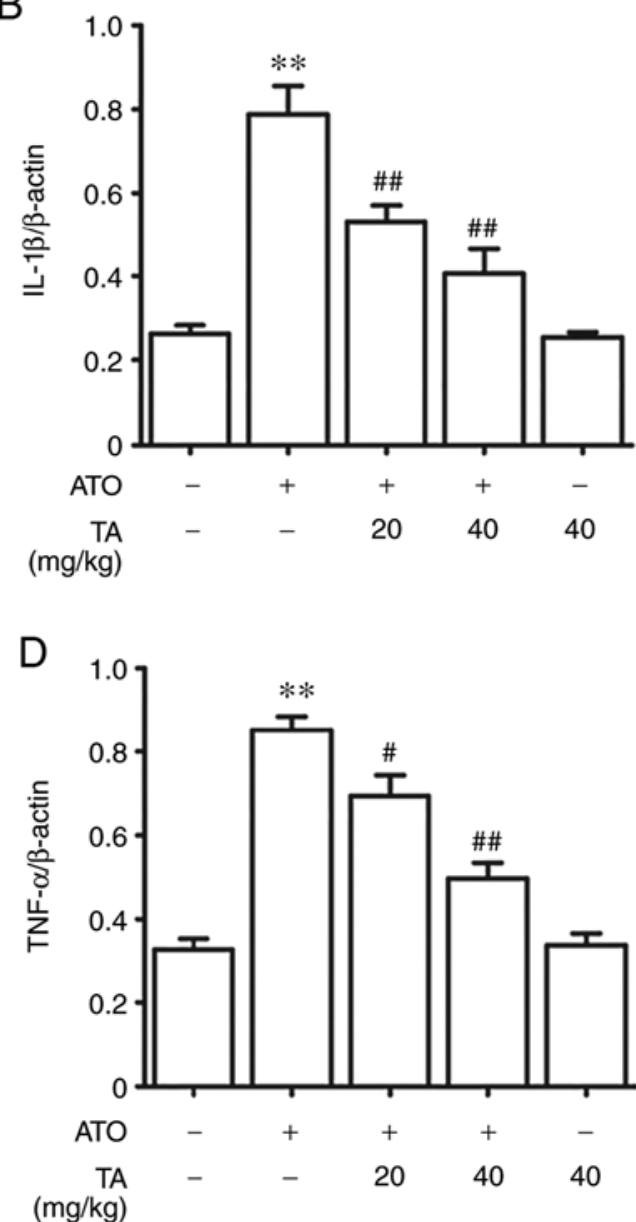

Figure 6. Effects of TA on the expression levels of IL-1 $\beta$, IL-6 and TNF- $\alpha$ in ATO-exposed rats. (A) Western blot analysis was used to assess the hepatic protein expression levels of (B) IL-1 $\beta,(\mathrm{C}) \mathrm{IL}-6$ and (D) TNF- $\alpha$. All results are presented as mean $\pm \mathrm{SEM}(\mathrm{n}=4) .{ }^{* *} \mathrm{P}<0.01$ vs. the control group; ${ }^{\#} \mathrm{P}<0.05,{ }^{\#} \mathrm{P}<0.01 \mathrm{vs}$. the ATO group. TA, tannic acid; ATO, arsenic trioxide; IL, interleukin; TNF, tumor necrosis factor.

A

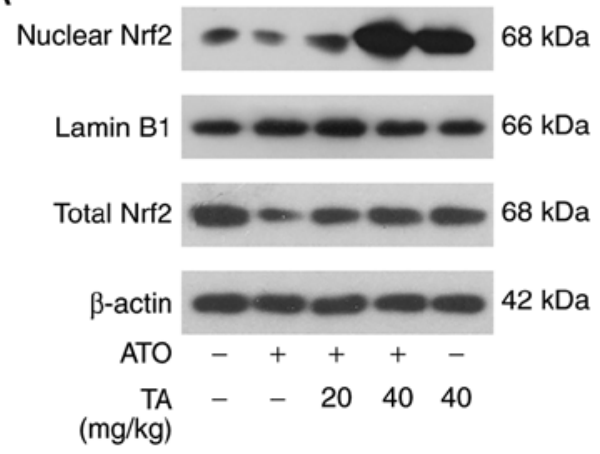

B

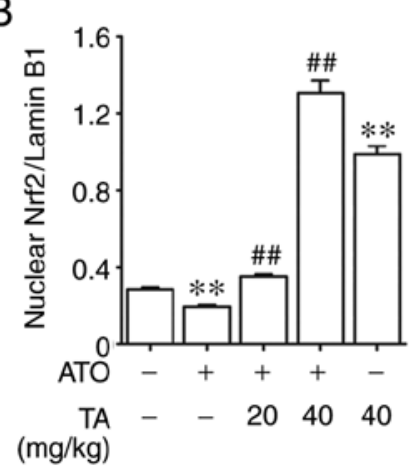

C

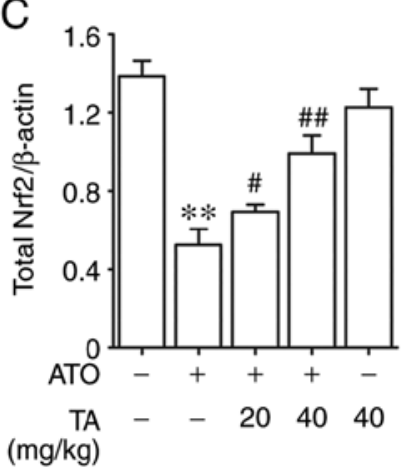

Figure 7. Effects of TA on Nrf2 activation in ATO-exposed rats. (A) Western blot analysis was used to assess the hepatic protein expression levels of (B) nuclear Nrf2 and (C) total Nrf2. All results are presented as the mean $\pm \mathrm{SEM}(\mathrm{n}=4) .{ }^{* *} \mathrm{P}<0.01$ vs. the control group; ${ }^{\#} \mathrm{P}<0.05,{ }^{\# \prime} \mathrm{P}<0.01$ vs. the ATO group. TA, tannic acid; ATO, arsenic trioxide; Nrf2, nuclear factor erythroid 2-related factor 2.

The protein expression level of Keap1 in ATO-induced rats increased significantly as shown in Fig. 8A and $\mathrm{B}(\mathrm{P}<0.01)$. Treatment with 20 or $40 \mathrm{mg} / \mathrm{kg}$ TA significantly reduced the expression level of Keap1 in the livers of ATO-induced rats $(\mathrm{P}<0.01)$. On the contrary, ATO-induced rats showed a marked decrease in the protein expression levels of HO-1, NQO1 and $\gamma$-GCS $(\mathrm{P}<0.05$ or $\mathrm{P}<0.01)$ (Fig. $8 \mathrm{~A}$ and $\mathrm{C}-\mathrm{E})$. Treatment with 20 or $40 \mathrm{mg} / \mathrm{kg}$ TA fortified the expression levels of HO-1, NQO1 and $\gamma$-GCS in the livers of ATO-induced rats $(\mathrm{P}<0.01)$. Compared against the control group, rats that only received $40 \mathrm{mg} / \mathrm{kg}$ TA showed non-significant changes in the protein expressions of Keap1, HO-1 and $\gamma$-GCS (P>0.05); however, showed significantly activated expression of NQO1 $(\mathrm{P}<0.01)$. 

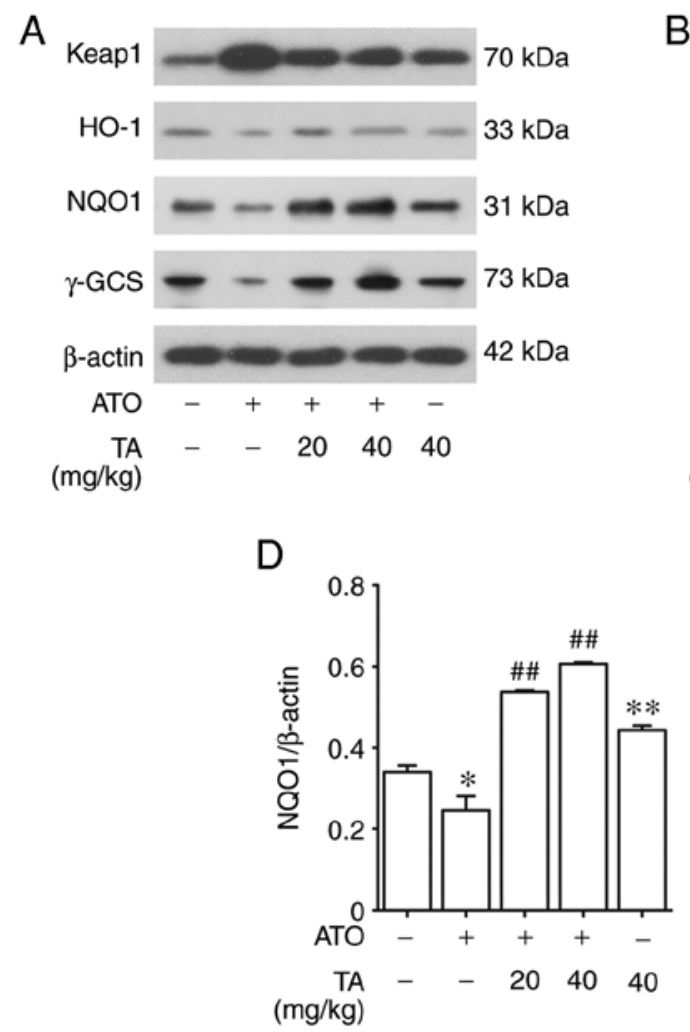
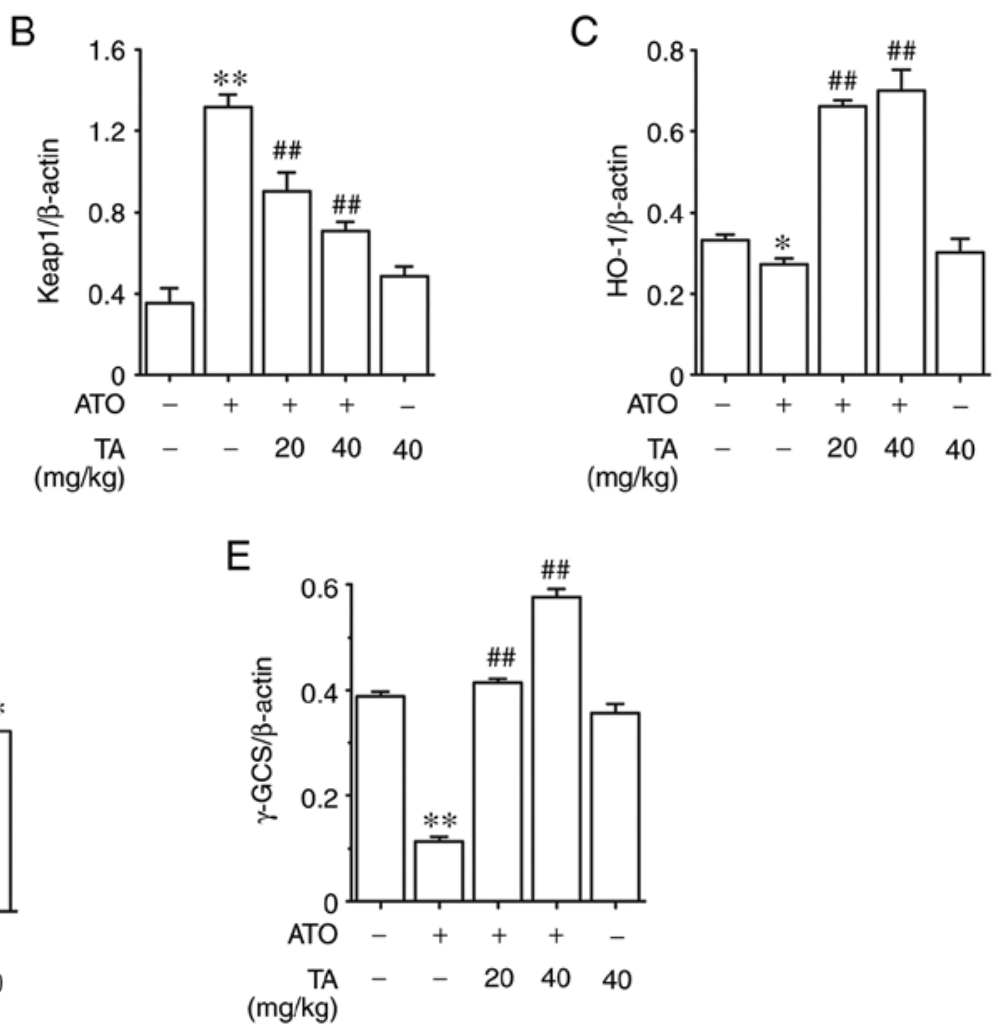

Figure 8. Effects of TA on the expression levels of downstream targets in the Nrf2 pathway in ATO-treated rats. (A) The hepatic protein expression levels of (B) Keap1, (C) HO-1, (D) NQO1 and (E) $\gamma$-GCS were measured by western blot analysis. All results are presented as the mean \pm SEM (n=4). "P<0.05, ${ }^{* *} \mathrm{P}<0.01$ vs. control group; ${ }^{\# \#} \mathrm{P}<0.01$ vs. ATO group. TA, tannic acid; ATO, arsenic trioxide. Nrf2, nuclear factor erythroid 2-related factor 2; Keap1, Kelch-like ECH-associated protein 1; HO-1, heme oxygenase-1; NQO1, NADPH quinine oxidoreductase-1, $\gamma$-GCS, $\gamma$-glutamylcysteine synthetase.

\section{Discussion}

Arsenic, as a pollutant and human carcinogen, produces a complex effect in organisms, including oxidative stress, apoptosis and inflammation (22). The cytotoxicity of arsenic trioxide (ATO) may limit its clinical application in cancer treatment. Thus, it makes sense to search for an appropriate antidote to ATO. Previous studies have investigated the relationship between complex mixtures containing tannic acid (TA) and arsenic compounds, such as aqueous extract of green tea leaves (23). It is reasonable to guess that TA may have a protective effect against ATO-induced liver injury. Accordingly, the present study focused on the assessment of the hepatic changes induced by ATO, as well as the therapeutic effect and underlying mechanisms of TA in rats.

It was found that ATO significantly induced liver injury in the present study, which was manifested in the formation of an abnormal histological central vein area and portal tract structure and increased circulating ALT and AST levels. Due to the fact that ALT and AST typically enter the bloodstream following an injury to the structural integrity of liver cells, the levels of ALT and AST in the serum have been generally regarded as representative indicators of hepatic damage (24). TA treatment exhibited hepatic protective effects as manifested by the improvement of pathological damage and a decrease in the levels of ALT and AST. Previous studies have shown that TA exhibited the same impact trend for these indicators in carbon tetrachloride or iron-overload-induced hepatotoxicity $(16,25)$. All the aforementioned evidence suggests that TA could be an effective natural compound for relieving various types of liver damage.

Oxidative stress, apoptosis and inflammation are common features of numerous diseases and play important roles in tumorigenesis $(26,27)$. Oxidative impairment following ATO exposure if significantly reflected by increased ROS and MDA and decreased SOD, CAT and GSH-Px $(28,29)$. The Bcl gene family is a critical regulatory gene in the regulation of apoptosis. Both Bax and $\mathrm{Bcl}-2$ belong to the Bcl family and play important roles in the regulation of apoptosis pathways. Therefore, Bcl-2 and Bax are often used to define the degree of apoptosis $(30,31)$. Moreover, as a cell death protease, caspase-3 plays a significant role in cell apoptosis $(29,32)$. Activation of apoptotic pathways finally results in the activation of caspase-3 (32). Caspase-3 is an 'effector' protease in the apoptosis cascade and is one of the main executors of apoptosis $(29,32)$. Caspase-3 activation can alter cell morphology and degrade DNA, sequentially triggering apoptosis. Accompanied by the production of a large amount of ROS, the permeability of the mitochondrial membrane increases significantly. Ultimately the apoptosis cascade reaction of caspases is triggered (33). Excessive oxidative stress evoked by ATO triggers some signaling pathways containing the activation of caspase-3 resulting in hepatic cell apoptosis. Consistent with previous researches (34-36), ATO promotes the apoptosis of hepatic cells, decreases significantly Bcl-2 expression and elevates Bax and caspase- 3 expression levels as demonstrated in the present study, which confirmed the occurrence of apoptosis in the hepatotoxic rats. Interestingly, ATO-induced 


\section{ATO toxicity $>$ Hepatic injury

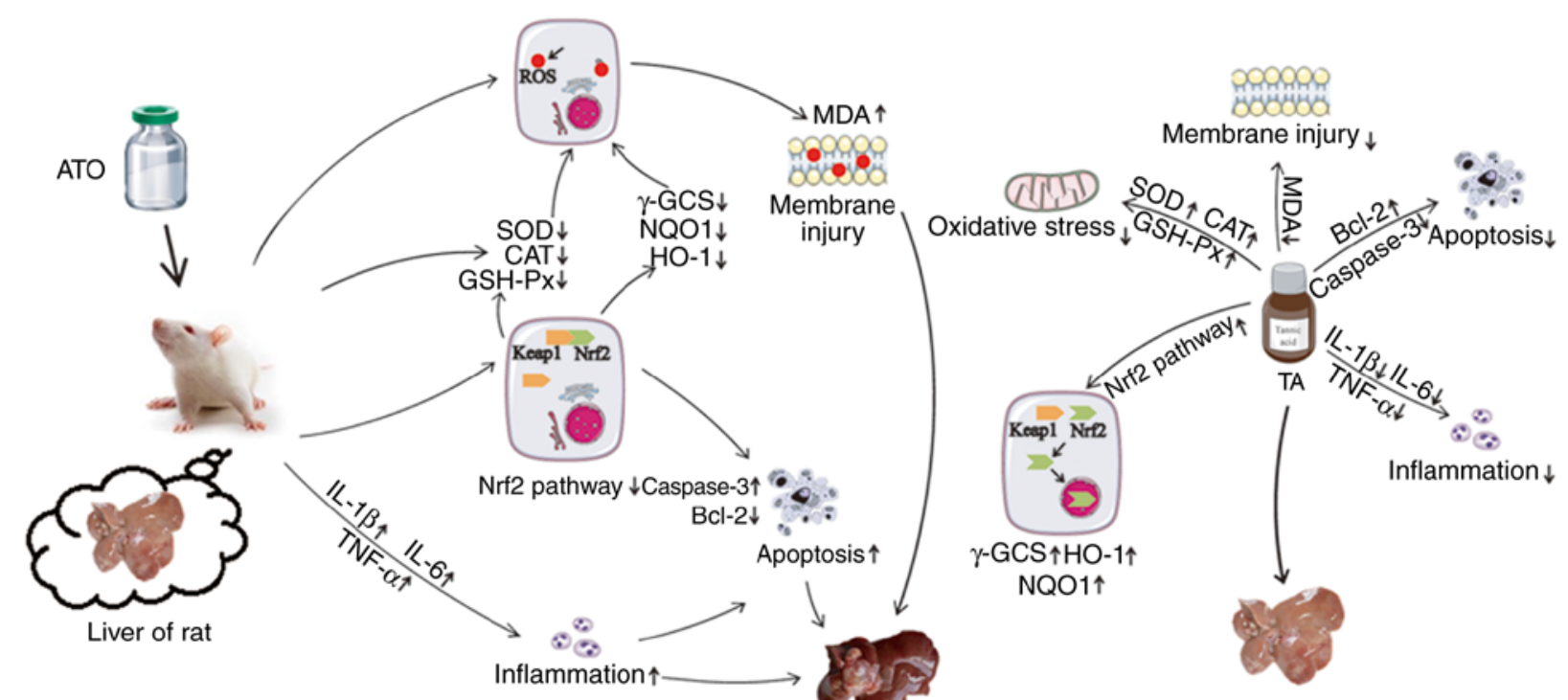

Hepatic injury

Hepatic protection

Figure 9. Effects of TA treatment on ATO-induced hepatic injury. TA stimulates the levels of SOD, CAT and GSH-Px, attenuates the levels of MDA and ROS TA is capable of suppression of the expression levels of caspase-3, Bax, IL-1 $\beta$, IL-6, TNF- $\alpha$ and Keap1, and activates expression levels of Bcl-2, nuclear Nrf2, total Nrf2, HO-1, NQO1 and $\gamma$-GCS. The protective effect of TA on ATO-induced hepatic injury may be associated with the attenuation of hepatic oxidative stress, apoptosis and inflammation by activating the Keap1-Nrf2/ARE pathway. TA, tannic acid; ATO, arsenic trioxide; SOD, superoxide dismutase; CAT, catalase; GSH-Px, glutathione peroxidase; MDA, malondialdehyde; ROS, reactive oxygen species; IL, interleukin; TNF, tumor necrosis factor; Nrf2, nuclear factor erythroid 2-related factor 2; Keap1, Kelch-like ECH-associated protein 1; HO-1, heme oxygenase-1; NQO1, NADPH quinine oxidoreductase-1, $\gamma$-GCS, $\gamma$-glutamylcysteine synthetase; ARE, antioxidant response element.

changes in Bax, Bcl-2 and caspase-3 expression levels were approximately restored to normal levels following treatment TA, ultimately decreasing the number of TUNEL-positive cells in the liver tissue. Taken together, the results suggest that TA inhibits the apoptosis of hepatic cells by increasing Bcl-2 expression and decreasing Bax and caspase- 3 expression as confirmed in our experiments. In the present study, we observed that ATO stimulated IL-1 $\beta$, IL- 6 and TNF- $\alpha$ protein expression levels, which aggravated inflammation. At the same time, it has been reported that Nrf2 improves the removal of ROS for cellular defense and plays a protective role against oxidative stress (37). Nrf2 controls Bcl-2 expression and apoptotic cell death with implications on the survival of cells (38). Furthermore, it has been evidenced that the activation of Nrf2 prevents proinflammatory cytokines, such as IL-1 $\beta$ and IL-6 (39). In the present study, it was found that TA alleviated oxidative stress, apoptosis and inflammation induced by ATO (Fig. 9). Therefore, we further investigated whether ATO and TA have effects on the Nrf2 pathway.

Nrf2 is a key transcription factor that regulates gene expression of a series of anti-oxidant proteins and detoxifying enzymes. Keap1, a redox-regulated substrate adaptor protein for a cullin3-dependent ubiquitin ligase complex, senses electrophilic or oxidative stresses and then arrests ubiquitination of Nrf2, leading to Nrf2 activation (40). In addition to this canonical pathway, one Nrf2 target p62/SQSTM1 (p62) competitively binds to Keap1 to activate Nrf2. p62 is a stress-inducible intracellular protein, which is known to regulate various signal transduction pathways involved in cell survival and cell death. p62 interacts with p62, NBR1, ERK1, and atypical PKC (aPKC) through Phox and Bem1 (PB1)-mediated homooligomerization or heterooligomerization to regulate the NF- $\mathrm{kB}$ signaling pathway (40).

The Nrf2-Keap1 signaling pathway is a considerable antioxidant defense mechanism that activates an adaptive cellular response against oxidative stress and participates in the toxicant metabolic and detoxifying process (41). Keap1 is a repressor of Nrf2 activity and plays a key role in its regulation. It was found that ATO significantly inhibited Nrf2 while increasing Keap1. This finding was consistent with the result that arsenic-induced reduction in antioxidant enzymes was more pronounced in Nrf2-inhibited cells, indicating that arsenic may inhibit the Nrf2 pathway $(42,43)$. The mechanism of arsenic in the inhibition of Nrf2 expression may be related to the acceleration of $\mathrm{Nrf} 2$ degradation and the promotion of Keap1 protein expression (44). These results revealed that TA treatment exhibited a facilitating effect on the Nrf2 pathway in increasing Nrf2 while inhibiting Keap1. Following evasion from Keap1, Nrf2 translocates to the nucleus, and activates the expression of a series of cytoprotective and antioxidative protein-dependent genes such as HO-1, NQO1 and $\gamma$-GCS (45). HO-1 is an inducer of bilirubin and carbon monoxide and thus provides protection against cell oxidative injury (46). NQO1, a member of the NAD $(\mathrm{P}) \mathrm{H}$ dehydrogenase family, encodes a cytoplasmic 2-electron reductase (47). Furthermore, $\gamma$-GCS is a rate-limiting enzyme of glutathione biosynthesis, which 
can detoxify certain deleterious xenobiotics through direct thiol conjugation. In brief, these are all important metabolism and antioxidant enzymes and play key roles in the control of signaling processes (48). In the present study, TA treatment increased the expression levels of HO-1, NQO1 and $\gamma$-GCS, which were inhibited by ATO. As suggested by the results of the present study, an underlying mechanism of TA in relation to antioxidant properties has been demonstrated as the guidance of antioxidants and phase II detoxifying enzymes by Nrf2 activation.

There are other issues which should be discussed in regards to this previous experiment. The dosage of TA used in this study was based on our previous experiments $(15-17,20)$, in which there were no significant changes in liver morphology, enzyme activities and in the expression levels of the majority of proteins. Our previous reseach on TA against ATO-induced nephrotoxicity hypothesized that TA may play a protective role through the $\mathrm{NF}-\kappa \mathrm{B} / \mathrm{Nrf} 2$ pathway by determining the protein levels of $\mathrm{NF}-\kappa \mathrm{B}, \mathrm{Nrf} 2$ and Keap1 (15). In the present research, we systematically studied the protective effect and mechanism of TA on liver injury induced by ATO. In addition to Nrf2 and Keap1, we also investigated the influence of TA on the protein expression levels of HO-1, NQO1, and $\gamma$-GCS in this signaling pathway. Additionally, dimercaptopropanol and its derivatives have been found to be used to clinically relieve acute intoxication (49); however, it was not set as a positive control drug in the present study, considering that the amount of ATO was still a small dose and could not cause acute poisoning. Interestingly, arsenic has been reported to activate the Nrf2-Keap1 signaling pathway in some types of cancer cells, due to mutations in Nrf2, which can be beneficial for cancer cell growth and self-protection (50). Based on the large number of previous studies and the results from the present study, we believe that the inhibitory effect of ATO on the Keap1-Nrf2/ARE signaling pathway in non-cancerous rats is reasonable. However, the regulation of TA on the Keap1-Nrf2 pathway in cancer cells needs further investigation.

In summary, TA, as a valuable dietary component or medicinal material, could mitigate the hepatic damage of ATO by inhibiting oxidative stress, apoptosis and inflammation, and the mechanisms that may be associated with the activation of the Keap1-Nrf2/ARE signaling pathway. The results of the present study could further reveal the molecular mechanisms of the beneficial effects of TA on ATO-induced liver injury.

\section{Acknowledgements}

Not applicable.

\section{Funding}

This work was supported by the Research Foundation of Administration of Traditional Chinese Medicine of Hebei Province, China (no. 2020188).

\section{Availability of data and materials}

The datasets used and/or analyzed during the current study are available from the corresponding author on reasonable request.

\section{Authors' contributions}

LC and XC contributed to the design of the experiments. ML, $\mathrm{YX}$ and YL conducted the experiments and obtained the data. JZ, JS and XH analyzed the data. ML and PL wrote the manuscript. PL, JZ and LC contributed to the manuscript revisions. All authors read the manuscript and approved the final version of the manuscript.

\section{Ethics approval and consent to participate}

All operating procedures regarding experimental animals were approved by the Ethics Committee for Animal Experiments of Hebei University of Chinese Medicine.

\section{Patient consent for publication}

Not applicable.

\section{Competing interests}

The authors declare that they have no competing interests.

\section{References}

1. Kim PG, Bridgham K, Chen EC, Vidula MK, Pozdnyakova O, Brunner AM and Fathi AT: Incident adverse events following therapy for acute promyelocytic leukemia. Leuk Res Rep 9: 79-83, 2018.

2. Benramdane L, Accominotti M, Fanton L, Malicier D and Vallon JJ: Arsenic speciation in human organs following fatal arsenic trioxide poisoning-a case report. Clin Chem 45: 301-306, 1999.

3. You BR and Park WH: Arsenic trioxide induces human pulmonary fibroblast cell death via increasing ROS levels and GSH depletion. Oncol Rep 28: 749-757, 2012.

4. Abhilash S, Siviyasankar R, Binu P, Arathi P and Harikumaran Nair R: Different administration patterns of docosahexaenoic acid in combating cytotoxic manifestations due to arsenic trioxide (acute promyelocytic leukemia drug) induced redox imbalance in hepatocytes. Prostaglandins Other Lipid Mediat 136: 64-75, 2018.

5. Ahmed S, Mahabbat-e Khoda S, Rekha RS, Gardner RM, Ameer SS, Moore S, Ekstrom EC, Vahter M and Raqib R: Arsenic-associated oxidative stress, inflammation, and immune disruption in human placenta and cord blood. Environ Health Perspect 119: 258-264, 2010.

6. Zheng Y, Yamaguchi H, Tian C, Lee MW, Tang H, Wang HG and Chen Q: Arsenic trioxide $(\mathrm{As}(2) \mathrm{O}(3))$ induces apoptosis through activation of Bax in hematopoietic cells. Oncogene 24: 3339-3347, 2005 .

7. Bao J, Ding R, Zou L, Zhang C, Wang K, Liu F, Li P, Chen M, Wan JB, Su H, et al: Forsythiae fructus inhibits B16 melanoma growth involving MAPKs/Nrf2/HO-1 mediated anti-oxidation and anti-inflammation. Am J Chin Med 44: 1043-1061, 2016.

8. Liu C, Xu H, Fu S, Chen Y, Chen Q, Cai Z, Zhou J and Wang Z: Sulforaphane ameliorates bladder dysfunction through activation of the Nrf2-ARE pathway in a rat model of partial bladder outlet obstruction. Oxid Med Cell Longev 2016: 7598294, 2016.

9. Hirotsu Y, Katsuoka F, Funayama R, Nagashima T, Nishida Y, Nakayama K, Engel JD and Yamamoto M: Nrf2-MafG heterodimers contribute globally to antioxidant and metabolic networks. Nucleic Acids Res 40: 10228-10239, 2012.

10. Liu D, Duan X, Dong D, Bai C, Li X, Sun G and Li B: Activation of the Nrf2 pathway by inorganic arsenic in human hepatocytes and the role of transcriptional repressor Bach1. Oxid Med Cell Longev 2013: 984546, 2013.

11. Zhao HJ, Li MJ, Zhang MP, Wei MK, Shen LP, Jiang M and Zeng T: Allyl methyl trisulfide protected against acetaminophen (paracetamol)-induced hepatotoxicity by suppressing CYP2E1 and activating Nrf2 in mouse liver. Food Funct 10: 2244-2253, 2019. 
12. Nepka C, Sivridis E, Antonoglou O, Kortsaris A, Georgellis A, Taitzoglou I, Hytiroglou P, Papadimitriou C, Zintzaras I and Kouretas D: Chemopreventive activity of very low dose dietary tannic acid administration in hepatoma bearing $\mathrm{C} 3 \mathrm{H}$ male mice. Cancer Lett 141: 57-62, 1999.

13. Gray JP, Mishin V, Heck DE and Laskin JD: Dietary tannic acid stimulates production of reactive oxygen intermediates and growth factor and inflammatory gene expression in human colon tumor cells. Cancer Rese 65: 1223, 2005.

14. Ninan N, Forget A, Shastri VP, Voelcker NH and Blencowe A: Antibacterial and anti-inflammatory $\mathrm{pH}$-responsive tannic acid-carboxylated agarose composite hydrogels for wound healing. ACS Appl Mater Interfaces 8: 28511-28521, 2016.

15. Jin W, Xue Y, Xue Y, Han X, Song Q, Zhang J, Li Z, Cheng J, Guan S, Sun S and Chu L: Tannic acid ameliorates arsenic trioxide-induced nephrotoxicity, contribution of NF- $\kappa \mathrm{B}$ and $\mathrm{Nrf} 2$ pathways. Biomed Pharmacother 126: 110047, 2020

16. Chu X, Wang H, Jiang YM, Zhang YY, Bao YF, Zhang X, Zhang JP, Guo H, Yang F, Luan YC and Dong YS: Ameliorative effects of tannic acid on carbon tetrachloride-induced liver fibrosis in vivo and in vitro. J Pharmacol Sci 130: 15-23, 2016.

17. Zhang J, Song Q, Han X, Zhang Y, Zhang Y, Zhang X, Chu X, Zhang $F$ and Chu L: Multi-targeted protection of acetaminophen-induced hepatotoxicity in mice by tannic acid. Int Immunopharmacol 47: 95-105, 2017.

18. Chung MY, Song JH, Lee J, Shin EJ, Park JH, Lee SH, Hwang JT and Choi HK: Tannic acid, a novel histone acetyltransferase inhibitor, prevents non-alcoholic fatty liver disease both in vivo and in vitro model. Mol Metab 9: 34-48, 2019.

19. Krajka-Kuźniak V,Paluszczak J, Szaefer H and Baer-Dubowska W: The activation of the Nrf2/ARE pathway in HepG2 hepatoma cells by phytochemicals and subsequent modulation of phase II and antioxidant enzyme expression. J Physiol Biochem 71: 227-238, 2015.

20. Zhang J, Cui L, Han X, Zhang Y, Zhang X, Chu X, Zhang F, Zhang Y and Chu L: Protective effects of tannic acid on acute doxorubicin-induced cardiotoxicity: Involvement of suppression in oxidative stress, inflammation, and apoptosis. Biomed Pharmacother 93: 1253-1260, 2017.

21. Hemmati AA, Olapour S, Varzi HN, Khodayar MJ, Dianat M, Mohammadian B and Yaghooti H: Ellagic acid protects against arsenic trioxide-induced cardiotoxicity in rat. Hum Exp Toxicol 37: 412-419, 2017.

22. Singh AP, Goel RK and Kaur T: Mechanisms pertaining to arsenic toxicity. Toxicol Int 18: 87-93, 2011.

23. Messarah M, Saoudi M, Boumendjel A, Kadeche L, Boulakoud MS and Feki AE: Green tea extract alleviates arsenic-induced biochemical toxicity and lipid peroxidation in rats. Toxicol Ind Health 29: 349-359, 2013.

24. Vermeulen NP, Bessems JG and Van De Straat R: Molecular aspects of paracetamol-induced hepatotoxicity and its mechanism-based prevention. Drug Metab Rev 24: 367-407, 1992.

25. Basu T, Panja S, Shendge AK, Das A and Mandal N: A natural antioxidant, tannic acid mitigates iron-overload induced hepatotoxicity in swiss albino mice through ROS regulation. Environ Toxicol 33: 603-618, 2018.

26. Ahmed SM, Luo L, Namani A, Wang XJ and Tang X: Nrf2 signaling pathway: Pivotal roles in inflammation. Biochim Biophys Acta Mol Basis Di 1863: 585-597, 2017.

27. Lushchak IV: Free radicals, reactive oxygen species, oxidative stress and its classification. Chem Biol Interact 224: 164-175, 2014

28. Sumedha NC and Miltonprabu S: Diallyl trisulfide ameliorates arsenic-induced hepatotoxicity by abrogation of oxidative stress, inflammation, and apoptosis in rats. Hum Exp Toxicol 34: 506-525, 2015

29. Adedara IA, Adebowale AA, Atanda OE, Fabunmi AT, Ayenitaju AC, Rocha JBT and Farombi EO: Selenium abates reproductive dysfunction via attenuation of biometal accumulation, oxido-inflammatory stress and caspase-3 activation in male rats exposed to arsenic. Environ Pollut 254: 113079-113090, 2019.

30. Imam F, Al-Harbi NO, Al-Harbi MM, Ansari MA, Al-Asmari AF Ansari MN, Al-Anazi WA, Bahashwan S, Almutairi MM, Alshammari M, et al: Apremilast prevent doxorubicin-induced apoptosis and inflammation in heart through inhibition of oxidative stress mediated activation of NF- $\mathrm{BB}$ signaling pathways. Pharmacol Rep 70: 993-1000, 2018.

31. Dash SK, Chattopadhyay S, Ghosh T, Dash SS, Tripathy S, Das B, Bag BG, Das D and Roy S: Self-assembled betulinic acid protects doxorubicin induced apoptosis followed by reduction of ROS-TNF- $\alpha$-caspase- 3 activity. Biomed Pharmacother 72 : 144-157, 2015
32. Van Opdenbosch $\mathrm{N}$ and Lamkanfi $\mathrm{M}$ : Caspases in cell death, inflammation, and disease. Immunity 50: 1352-1364, 2019.

33. Oliveira PJ, Santos MS and Wallace KB: Doxorubicin-induced thiol-dependent alteration of cardiac mitochondrial permeability transition and respiration. Biochemistry (Mosc) 71: 194-199, 2006.

34. Liu W, Gao FF, Li Q, Lv JW, Wang Y, Hu PC, Xiang QM and Wei L: Protective effect of Astragalus polysaccharides on liver injury induced by several different chemotherapeutics in mice. Asian Pac J Cancer Prev 15: 10413-10420, 2014.

35. Wu Z, Zhang Y, Song T, Song Q, Zhang Y, Zhang X, Han X, Zhang $\mathrm{J}$ and Chu L: Magnesium isoglycyrrhizinate ameliorates doxorubicin-induced acute cardiac and hepatic toxicity via antio-xidant and anti-apoptotic mechanisms in mice. Exp Ther Med 15: 1005-1012, 2018.

36. Miltonprabu S, Sumedha NC and Senthilraja P: Diallyl trisulfide, a garlic polysulfide protects against As-induced renal oxidative nephrotoxicity, apoptosis and inflammation in rats by activating the Nrf2/ARE signaling pathway. Int Immunopharmacol 50: 107-120, 2017.

37. Singh S, Vrishni S, Singh BK, Rahman I and Kakkar P: Nrf2-ARE stress response mechanism: A control point in oxidative stress-mediated dysfunctions and chronic inflammatory diseases. Free Radic Res 44: 1267-1288, 2010.

38. Niture SK and Jaiswal AK: Nrf2 protein up-regulates antiapoptotic protein Bcl-2 and prevents cellular apoptosis. J Biol Chem 287: 9873-9886, 2012.

39. Kobayashi EH, Suzuki T, Funayama R, Nagashima T, Hayashi M, Sekine H, Tanaka N, Moriguchi T, Motohashi H, Nakayama K and Yamamoto M: Nrf2 suppresses macrophage inflammatory response by blocking proinflammatory cytokine transcription. Nat Commun 7: 11624, 2016.

40. Katsuragi Y, Ichimura Y and Komatsu M: Regulation of the Keap1-Nrf2 pathway by p62/SQSTM1. In: Oxidative Toxicology. Johnson J, Puga A, Wallace KB and Zhang D (eds). Vol 1. Current Opinion in Toxicology, pp54-61, 2016

41. Shi L, Hao Z, Zhang S, Wei M, Lu B, Wang Z and Ji L: Baicalein and baicalin alleviate acetaminophen-induced liver injury by activating Nrf2 antioxidative pathway: The involvement of ERK1/2 and PKC. Biochem Pharmacol 150 9-23, 2018

42. Shafik NM and El Batsh MM: Protective effects of combined selenium and punica granatum treatment on some inflammatory and oxidative stress markers in arsenic-induced hepatotoxicity in rats. Biol Trace Elem Res 169: 121-128, 2016

43. Vineetha RC, Archana V, Binu P, Arathi P and Nair RH: $\mathrm{L}$-ascorbic acid and $\alpha$-Tocopherol reduces hepatotoxicity associated with arsenic trioxide chemotherapy by modulating Nrf2 and Bcl 2 transcription factors in chang liver cells. Nutr Cancer 70: 684-696, 2018.

44. Ugun-Klusek A, Tatham MH, Elkharaz J, Constantin-Teodosiu D, Lawler K, Mohamed H, Paine SM, Anderson G, John Mayer R, Lowe J, et al: Continued 26S proteasome dysfunction in mouse brain cortical neurons impairs autophagy and the Keap1-Nrf2 oxidative defence pathway. Cell Death Dis 8: e2531, 2017.

45. Baird L and Dinkova-Kostova AT: The cytoprotective role of the Keap1-Nrf2 pathway. Arch Toxicol 85: 241-272, 2011.

46. Takahashi T, Morita K, Akagi R and Sassa S: Heme oxygenase-1: A novel therapeutic target in oxidative tissue injuries. Curr Med Chem 11: 1545-1561, 2004

47. Xu D, Hu L, Xia X, Song J, Li L, Song E and Song Y: Tetrachlorobenzoquinone induces acute liver injury, up-regulates HO-1 and NQO1 expression in mice model: The protective role of chlorogenic acid. Environ Toxicol Pharmacol 37: 1212-1220, 2014.

48. Liu X, Chen K, Zhu L, Liu H, Ma T, Xu Q and Xie T: Soyasaponin $\mathrm{Ab}$ protects against oxidative stress in HepG2 cells via Nrf2/HO-1/NQO1 signaling pathways. J Functional Foods 45: 110-117, 2018.

49. Aaseth J, Skaug MA, Cao Y and Andersen O: Chelation in metal intoxication-Principles and paradigms. J Trace Elem Med Biol 31: 260-266, 2015.

50. Lau A, Whitman SA, Jaramillo MC and Zhang DD Arsenic-mediated activation of the Nrf2-Keap1 antioxidant pathway. J Biochem Mol Toxicol 27: 99-105, 2013. 